Saudi Journal of Oral and Dental Research

Abbreviated Key Title: Saudi J Oral Dent Res

ISSN 2518-1300 (Print) |ISSN 2518-1297 (Online)

Scholars Middle East Publishers, Dubai, United Arab Emirates

Journal homepage: https://saudijournals.com

\title{
Prevalence of Dental Caries in 11-14 Years Old School Children in Endemic Fluoride Areas of Haryana, India
}

\author{
Radhey Shyam ${ }^{1}$, Manjunath BC ${ }^{2}$, Adarsh Kumar ${ }^{3}$, Vipul Yadav ${ }^{4}$, Mansi Mendiratta ${ }^{5 *}$, Madhavi Wig ${ }^{6}$ \\ ${ }^{1}$ Senior Resident, Department of Public Health Dentistry, Postgraduate Institute of Dental Sciences, Pt. B.D Sharma University of Health Sciences, \\ Rohtak, Haryana, India \\ ${ }^{2}$ Senior Professor and Head, Department of Public Health Dentistry, Postgraduate Institute of Dental Sciences, Rohtak, Haryana, India \\ ${ }^{3}$ Professor, Department of Public Health Dentistry, Postgraduate Institute of Dental Sciences, Rohtak, Haryana, India \\ ${ }^{4}$ Assistant Professor, Department of Public Health Dentistry, Postgraduate Institute of Dental Sciences, Rohtak, Haryana, India \\ ${ }^{5}$ Postgraduate student, Department of Public Health Dentistry, Postgraduate Institute of Dental Sciences, Rohtak, Haryana, India \\ ${ }^{6}$ Postgraduate student, Department of Public Health Dentistry, Postgraduate Institute of Dental Sciences, Rohtak, Haryana, India
}

DOI: $10.36348 /$ sjodr.2021.v06i02.005

| Received: 08.02.2021 | Accepted: 22.02.2021 | Published: 24.02.2021

*Corresponding author: Dr. Mansi Mendiratta

\section{Abstract}

Background: Dental caries remains public health problem worldwide. It may develop in an early stage of life as soon as teeth erupt. Dental caries exhibits diminishing trends in most of the developed countries, but still increasing trends seen in many developing countries. Aim: To assess the prevalence of dental caries in 11-14years old school children in endemic fluoride areas of Haryana, India. Materials and methods: This study was a part of a cross sectional descriptive study which was conducted among 2200 school children of 11-14 years old age in endemic fluoride areas of Haryana, India. After obtaining the data from central ground water board, Haryana, 3 districts were selected using cluster random sampling out of 14 endemic fluoride districts. Dental examination was carried out by a single trained investigator. Sociodemographic details of children were recorded and WHO basic oral health assessment criteria for children modified (2013) was used for assessment of dental caries. The data were entered in Microsoft Excel and analyzed using SPSS 18 package for relevant statistical comparison. Results: In the present study 997 (45.3\%) were males and $54.7 \%$ were

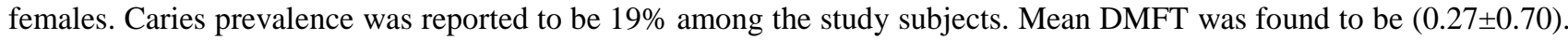
Conclusion: The present study revealed that the prevalence of dental caries and DMFT was low among children. The reason behind this may be due to high concentration of fluoride in drinking water in those areas.

Key words: Dental caries, school children, endemic areas.

Copyright (C) 2021 The Author(s): This is an open-access article distributed under the terms of the Creative Commons Attribution 4.0 International License (CC BY-NC 4.0) which permits unrestricted use, distribution, and reproduction in any medium for non-commercial use provided the original author and source are credited.

\section{INTRODUCTION}

Dental caries, despite availability of many preventive and treatment measure, remains public health problem worldwide. It is mainly found in the low socioeconomic groups. It may develop in an early stage of life as soon as teeth erupt. Dental caries manifests clinically as a course of action from initial visual change in enamel to frank cavitations extending to dentin and dental pulp [1].

If it is not treated in time, it may progress to more severe stages which lead to pain, difficulty in mastication and poor oral health. Although it is not a life threatening diseases, but due to its wide spread that affects school children result in social, psychological problems and other sever complications affecting oral health quality of life of school children. This burden of dental diseases also imposes financial problems on their families [2, 3].

Dental caries pattern exhibiting diminishing trends in most of the developed countries, but still increasing trends seen in many developing countries and is reported to be as high as $70 \%$ [4]. This may be due to availability of various preventable measures lie fluoride varnishes, APF gel and pit and fissure sealants it shows decreasing trends in most of developed world. The impact is far worse in developing countries, like India, where the prevalence of dental caries ranges from $30 \%-65 \%$ making it the most prevalent chronic disease among schoolchildren [5].

Various prevalence studies may be helpful in designing effective preventive and treatment strategies peoples who are at higher risk. There is lack of data 
Radhey Shyam et al; Saudi J Oral Dent Res, Feb, 2021; 6(2): 105-108

regarding dental caries prevalence in endemic fluoride areas of Haryana, India. Hence the present study was undertaken to assess the prevalence of dental caries in 11-14 years old school children in endemic fluoride areas of Haryana, India.

\section{MATERIALS AND METHODS}

This study was a part of a cross sectional descriptive study which was conducted among 2200 school children of 11-14 years old age in endemic fluoride areas of Haryana, India from August 2015 to February 2016[3].

Ethical clearance was obtained from the Ethics Committee of the Post Graduate Institute of Dental Sciences, Rohtak (PGIDS/IEC/2015/56) after explaining detail of the procedure. This study was conducted according to STROBE guidelines for observational studies. Before conducting the study, permission was obtained from the District Education Officer and concerned school authorities. After explaining the purpose and details of the study, a written informed consent was obtained from the parents of all children aged 11-14 years.

After obtaining the data from central ground water board, Haryana, 3 districts were selected using cluster random sampling out of 14 endemic fluoride districts. In these three districts water fluoride concentrations ranged from $0.23-4.30 \mathrm{ppm}$ [6].

Based on simple random sampling 2 tehsils from each districts were selected. Six schools were selected from each tehsil out of which four schools were from rural areas and two schools were from urban areas. Assuming 40 as average cluster size of children approximately 30-50 school children were selected.

Children present on the day of examination and who were willing to participate in the survey were included, whereas those who were uncooperative and had a history of systemic diseases and developmental anomalies were excluded. Training and calibration of the examiner was done in the Department of Public Health Dentistry, PGIDS, Rohtak, and the intraexaminer's reliability showed a good agreement (89\%).

Dental examination was carried out by a single trained investigator. Socio-demographic details of children were recorded and WHO basic oral health assessment criteria for children modified [7] was used for assessment of dental caries. Dental examination of the children was done using mouth mirror and WHO probe. A set of 60 autoclaved instruments were carried for clinical examination of children. If any children required immediate care, they were referred to the Department of Public Health Dentistry PGIDS Rohtak for further treatment.

\section{STATISTICAL ANALYSIS}

The data were entered in Microsoft Excel and analyzed using SPSS 18 package for relevant statistical comparison. Descriptive and inferential statistics were used. Chi-square tests were used for the comparison of proportions. Kruskal-Wallis test was used to find significant mean DMFT across different age groups and Mann-Whitney U-test was used to find difference of mean DMFT against gender. $\mathrm{p}<0.05$ was considered as statistically significant.

\section{RESULTS \\ Distribution of subjects according to age, gender}

The present study was conducted among 2200 study participants who were of age 11-14 years where $997(45.3 \%)$ were males and $54.7 \%$ were females. The mean age of study population was $12.38 \pm 1.07$ years. Table 1 shows the characteristic distribution of study population.

Table 2 shows that overall caries prevalence was reported to be $19 \%$ among the study subjects. Higher caries prevalence of $22 \%$ was reported among 14 year old children than 11 to 13 years old children. Females were found to have higher caries prevalence (20\%) than males $(18 \%)$, but this distribution was statistically non significant.

Table 3 shows that mean DMFT was higher among the 14 years old children when compared to other age groups of study. This was found to be statistically significant. Table 4 shows that mean DMFT was higher among the female student $(0.30 \pm 0.751)$ than male student $(0.23 \pm 0.644)$ and this difference was statistically found significant. Overall mean DMFT was found to be $(0.27 \pm 0.70)$.

Table-1: Age wise distribution of the study subjects

\begin{tabular}{|l|l|l|l|l|l|l|}
\hline Age & \multicolumn{1}{|l|}{ Male } & \multicolumn{3}{l|}{ Female } & \multicolumn{2}{l|}{ Total } \\
\hline & $\mathrm{N}$ & $\%$ & $\mathrm{~N}$ & $\%$ & $\mathrm{~N}$ & $\%$ \\
\hline $\mathbf{1 1}$ & 250 & 25.1 & 336 & 27.9 & 586 & 26.7 \\
\hline $\mathbf{1 2}$ & 282 & 28.3 & 326 & 27.1 & 608 & 27.6 \\
\hline $\mathbf{1 3}$ & 275 & 27.5 & 308 & 25.6 & 583 & 26.5 \\
\hline $\mathbf{1 4}$ & 190 & 19.1 & 233 & 19.4 & 423 & 19.2 \\
\hline Total & 997 & 45.3 & 1203 & 54.7 & 2200 & 100 \\
\hline
\end{tabular}

Table-2: Caries prevalence among study subjects

\begin{tabular}{|l|l|l|}
\hline \multicolumn{1}{|c|}{ Age } & Caries prevalence & p value \\
\hline 11 & 20.0 & \multirow{2}{*}{0.08} \\
\hline 12 & 20.0 & \\
\hline 13 & 16.0 & \\
\hline 14 & 22.0 \\
\hline Total & $\mathbf{1 9 . 0} \mathrm{p}<0.05$ & \\
\hline \multicolumn{2}{|c|}{} \\
\end{tabular}


Radhey Shyam et al; Saudi J Oral Dent Res, Feb, 2021; 6(2): 105-108

Table-3: Mean DMFT according to age groups

\begin{tabular}{|l|l|l|}
\hline Age & Mean DMFT & p value \\
\hline 11 & $0.23 \pm 0.623$ & \multirow{2}{*}{0.05} \\
\cline { 1 - 2 } & $0.26 \pm 0.667$ & \\
\hline 13 & $0.22 \pm 0.636$ & \\
\hline 14 & $0.39 \pm 0.914$ & \\
\hline
\end{tabular}

Table-4: Mean DMFT according to Gender

\begin{tabular}{|l|l|l|}
\hline Gender & Mean DMFT & p value \\
\hline Male & $0.23 \pm 0.644$ & 0.00 \\
\cline { 1 - 2 } Female & $0.30 \pm 0.751$ & \\
\hline
\end{tabular}

\section{DISCUSSION}

It has been proved from various studies around the globe that dental caries is one of most widely distributed dental diseases. Its burden is increasing in the developing countries like India and other Africans countries reason behind this may be lack of preventive strategies which are present in European countries like pit and fissure sealants, water fluoridation programs [8].

Caries prevalence in the present study was found to be lower than Indian studies by Ghanghas $M$ et al. [4] Janakiram C et al. [8] Shekhar et al. [9] Shivkumar et al. [10] Abraham et al.[11] Also the index age groups of 12 years also have lower caries prevalence than their counterpart studies like Praveena S et al. [12] Shaillee F et al. [13] and Sukhabogi JR et al.[14]

The presence of low dental caries prevalence of the study population could be due to the fact that this study was conducted among the endemic fluoride areas of Haryana. This fluoride which is ingested as drinking water as well as ingredients of crops and vegetables which is cultivated in present study areas. This fluoride may be act as preventable factor for development of dental caries.

However prevalence of dental caries varies accordingly change of geographic condition. The difference between the caries prevalence may be due to the difference in the socio-demographic factors, cultural factors and dietary factors.

Mean DMFT of the study population was found to be $0.27 \pm 0.70$ which was similar to other studies carried out by Prabhakar J et al. [15] and less than from other studies done by Aparna $\mathrm{M}$ et al. [16] Reddy KS et al. [17] and Jain A et al. [18] The D score contributed maximally for DMFT scores similar to that reported by Singh S et al. [19] Mahejabeen et al. [20] and Tyagi $\mathrm{P}[21]$.

Index age group of 12 years old had lower mean DMFT as compare to other studies by Vijayata Sharva V et al. [22] Shaillee F et al. [13] and Mahesh $\mathrm{KP}$ et al. [23] and children of 14 years age group were having higher mean DMFT than other age groups.
Females had higher value of mean DMFT than males and the difference was found to be significant. This is in accordance with other studies by Sogi et al. [24] and al-Shammery et al. [25] The reason for the high DMFT in females may be due to that teeth erupts early in females than males and other reason may be the females are having habits of longer indoor stay than males which leads to more intake of diet and other sugary products.

However dental caries is a multi-factorial disease which is having interplay of many social environmental and oral hygiene factors all these factors have a marked effect on dental caries prevalence. These remain undiscovered in present study and hence further research should be conducted to evaluate the effect of these untouched factors.

\section{CONCLUSION}

The present study evaluated the prevalence of dental caries and it was found to be low among children also the mean DMFT was found to be low. The reason behind this may be due to high concentration of fluoride in drinking water in those areas.

\section{REFERENCES}

1. Shyam, R., Manjunath, B. C., Kumar, A., Narang, R., Goyal, A., \& Piplani, A. (2017). Assessment of dental caries spectrum among 11 to 14-year-old school going children in India. Journal of clinical and diagnostic research: JCDR, 11(6), ZC78.

2. Alsumait, A., ElSalhy, M., Raine, K., Cor, K., Gokiert, R., Al-Mutawa, S., \& Amin, M. (2015). Impact of dental health on children's oral healthrelated quality of life: a cross-sectional study. Health and quality of life outcomes, 13(1), $1-10$.

3. Shyam, R., Chaluvaiah, M. B., Kumar, A., Pahwa, M., Rani, G., \& Phogat, R. (2020). Impact of dental fluorosis on the oral health related quality of life among 11-to 14-year-old school children in endemic fluoride areas of Haryana (India). International dental journal, 70(5), 340346.

4. Ghanghas, M., Kumar, A., Manjunath, B. C., Narang, R., Goyal, A., \& Kundu, H. (2017). Prevalence of early childhood caries in 3-to 5-yearold preschool children in Rohtak City, Haryana. Journal of Indian Association of Public Health Dentistry, 15(4), 344.

5. Shyam, R., Manjunath, B. C., Kumar, A., Narang, R., \& Ghanghas, M. (2019). Relationship of sociodemographic factors on dental caries experience among 11-14-year-old schoolchildren in India. Indian Journal of Dental Research, 30(6), 948.

6. Yadav, J. P., Lata, S., Kataria, S. K., \& Kumar, S. (2009). Fluoride distribution in groundwater and survey of dental fluorosis among school children in 
Radhey Shyam et al; Saudi J Oral Dent Res, Feb, 2021; 6(2): 105-108

the villages of the Jhajjar District of Haryana, India. Environmental geochemistry and health, 31(4), 431-438.

7. Petersen, P.E., \& Baez, R.J. (2013). Oral Health Surveys: Basic Methods. World Health Organization, Geneva. 5th Ed, 94.

8. Janakiram, C., Antony, B., Joseph, J., \& Ramanarayanan, V. (2018). Prevalence of Dental Caries in India among the WHO Index Age Groups: A Meta-Analysis. Journal of Clinical \& Diagnostic Research, 12(8).

9. Shekar, C., Cheluvaiah, M. B., \& Namile, D. (2012). Prevalence of dental caries and dental fluorosis among 12 and 15 years old school children in relation to fluoride concentration in drinking water in an endemic fluoride belt of Andhra Pradesh. Indian journal of public health, 56(2), 122.

10. Sivakumar, V., Jain, J., Haridas, R., Paliayal, S., Rodrigues, S., \& Jose, M. (2016). Oral health status of Tibetan and local school children: a comparative study. Journal of clinical and diagnostic research: JCDR, 10(11), ZC29.

11. Abraham, A., Pullishery, F., \& Raghavan, R. (2016). Dental caries and calculus status in children studying in Government and Private Schools in Malappuram, Kerala, India. IAIM, 3(3), 35-41.

12. Praveena, S., Thippeswamy, H. M., Nanditha, K., \& Kalyana Chakravarthy, P. (2013). Relationship of oral hygiene practices and dental caries among school children of Sullia Taluk, Karnataka, South India. Global J Med Res, 13, 9-14.

13. Shailee, F., Sogi, G. M., Sharma, K. R., \& Nidhi, P. (2012). Dental caries prevalence and treatment needs among 12-and 15-Year old schoolchildren in Shimla city, Himachal Pradesh, India. Indian Journal of Dental Research, 23(5), 579.

14. Sukhabogi, J. R., Shekar, C. B. R., Hameed, I. A., Ramana, I. V., \& Sandhu, G. (2014). Oral health status among 12 and 15 year old children from government and private schools in Hyderabad, Andhra Pradesh, India. Annals of medical and health sciences research, 4(3), 272-277.

15. Prabakar, J., John, J., \& Srisakthi, D. (2016). Prevalence of dental caries and treatment needs among school going children of Chandigarh. Indian Journal of Dental Research, 27(5).
16. Aparna, M., Sreekumar, S., Thomas, T., \& Hedge, V. (2018). Assessment of dental caries experience among 5-16 year old school going children of Mangalore, Karnataka, India: a cross-sectional study. Ann Essences Dent, 10(1), 12-17.

17. Reddy, K. S., Reddy, S., Ravindhar, P., Balaji, K., Reddy, H., \& Reddy, A. (2017). Prevalence of dental caries among 6-12 years school children of Mahbubnagar District, Telangana State, India: A cross-sectional study. Indian Journal of Dental Sciences, 9(1), 1.

18. Jain, A., Jain, V., Suri, S. M., \& Jain, R. K. (2016). Prevalence of dental caries in male children from 3 to 14 years of age of Bundelkhand region, India. Int J Community Med Public Health, 3(4), 787-790.

19. Singh, S., Vijayakumar, N., Priyadarshini, H. R., \& Shobha, M. (2012). Prevalence of early childhood caries among 3-5 year old pre-schoolers in schools of Marathahalli, Bangalore. Dental research journal, 9(6), 710.

20. Mahejabeen, R., Sudha, P., Kulkarni, S.S., Anegundi, R. (2006). Dental caries prevalence among preschool children of Hubli: Dharwad city. J Indian Soc Pedod Prev Dent, 24:19-22.

21. Tyagi, P. (2009). The prevalence and pattern of dental caries in preschool children. People's J Sci Res, $2: 1-4$.

22. Sharva, V., Khare, P., Reddy, V., Jain, M., Khare, A., Singh, P. (2017). Dental caries prevalence and treatment needs among 12- and 15-year-old schoolgoing children of rural and Urban Areas of Bhopal District, India. J Indian Assoc Public Health Dent, 15:340-3.

23. Kumar, P. M., Joseph, T., Varma, R. B., \& Jayanthi, M. (2005). Oral health status of 5 years and 12 years school going children in Chennai cityAn epidemiological study. Journal of Indian Society of Pedodontics and Preventive Dentistry, 23(1), 17.

24. Sogi, G., \& Bhaskar, D. J. (2001). Dental caries and oral hygiene status of 13-14 year old school children of Davangere. Journal of the Indian Society of Pedodontics and Preventive Dentistry, 19(3), 113-117.

25. Al- Shammery, A. R., Guile, E. E., \& EI- Backly, M. (1990). Prevalence of caries in primary school children in Saudi Arabia. Community Dentistry and Oral Epidemiology, 18(6), 320-321. 